\title{
Effects of strength level and loading frequency on very-high-cycle fatigue behavior for a bearing steel
}

\author{
Aiguo Zhao, Jijia Xie, Chengqi Sun, Zhengqiang Lei, Youshi Hong* \\ State Key Laboratory of Nonlinear Mechanics, Institute of Mechanics, Chinese Academy of Sciences, Beijing 100190, China
}

\section{A R T I C L E I N F O}

\section{Article history:}

Received 16 August 2011

Received in revised form 4 November 2011

Accepted 20 November 2011

Available online 2 December 2011

\section{Keywords:}

Very-high-cycle fatigue

Strength level

Frequency effect

Crack initiation

Fatigue mechanism

\begin{abstract}
A B S T R A C T
Rotating bending $(52.5 \mathrm{~Hz})$ and ultrasonic $(20 \mathrm{kHz})$ fatigue tests were performed on the specimens of a bearing steel, which were quenched and tempered at $150^{\circ} \mathrm{C}, 300^{\circ} \mathrm{C}, 450^{\circ} \mathrm{C}$ and $600{ }^{\circ} \mathrm{C}$, respectively, to investigate the influence of strength level and loading frequency on the fatigue behavior in veryhigh-cycle regime. Influences on fatigue resistance of materials, characteristics of $S-N$ curves and transition of crack initiation site were discussed. The specimens with higher strength showed interior fracture mode in very-high-cycle regime and with slight frequency effect, otherwise cracks all initiate from the surface and the fatigue strength was much higher under ultrasonic cycling.
\end{abstract}

(c) 2011 Elsevier Ltd. All rights reserved.

\section{Introduction}

In many industries, the required design lifetime of some components exceeds $10^{7}$ loading cycles, such as aircrafts (gas turbine disks $10^{10}$ cycles), ships (big diesel engine $10^{9}$ cycles), railways (high speed train $10^{9}$ cycles), and automobiles (car engine $10^{8}$ cycles) [1]. It is well known that the $S-N$ curves of low-strength steels usually tend to a limit at $10^{7}$ cycles by which the fatigue limit is defined, i.e. a stress level below which fatigue failure does not occur and it has been used as a design stress for machine components. However, in recent years, it has been reported that the fatigue failure of some high-strength steels and case-hardened steels still occurs at stress levels below the conventional fatigue limit in the life region greater than $10^{7}$ cycles [2-11]. Therefore, it is no longer safe to use the conventional fatigue design standard, especially for high-strength steels.

For low and medium strength steels, fatigue cracks tend to initiate from specimen surface and there is a common relation between fatigue limit and tensile strength: $\sigma_{w}=\sigma_{b} / 2$ [6,12]. The data collected by Abe et al. [12] show that for those low alloy steels of $\sigma_{b} \leqslant 1200 \mathrm{MPa}$, the relation is quite applicable. However, while $\sigma_{b}>1200 \mathrm{MPa}$, the ratio of fatigue limit to tensile strength is relatively low and the fracture tends to initiate from internal defects such as inclusions or cavities.

A classical method to determine the infinite fatigue life is to use Gaussian functions $[1,13]$. The fatigue limit is given by the average

\footnotetext{
* Corresponding author. Tel.: +86 10 82543966; fax: +86 1062561284 .

E-mail address: hongys@imech.ac.cn (Y. Hong).
}

alternating stress $\sigma_{w}$, and the probability of fracture is given by the standard deviation of the scatter $(s)$. It is said that the values of $\sigma_{w}-3 s$ gives a probability of fracture close to zero, where $s$ is generally taken as $10 \mathrm{MPa}$. Then the true infinite fatigue limit should be $\sigma_{w}$ minus $30 \mathrm{MPa}$. However, the study by Bathias et al. [7] showed that for many materials, the difference between the fatigue strength at $10^{6}$ and $10^{9}$ was larger than $50 \mathrm{MPa}$, especially for high-strength steels. Sometimes the difference could even reach to $200 \mathrm{MPa}$. The reason why the change of strength level has such a great effect on very-high-cycle fatigue (VHCF) behavior of materials is not clear.

In recent years, some researchers apply piezoelectric fatigue systems to accelerate testing of specimens at a frequency of $20 \mathrm{kHz}$, namely ultrasonic fatigue testing [14-18]. From $52.5 \mathrm{~Hz}$ to $20 \mathrm{kHz}$, there is an increase in strain rate of 2-3 orders of magnitude. Whether the data acquired from ultrasonic testing can be equivalent to those obtained by conventional frequency testing is dubious.

Laird and Charsley [19] gave an overview of frequency effect on cyclic plastic deformation, dislocation movement, damage localization and fatigue crack growth in pure fcc and bcc metals, and Mayer [20] gave a more detailed review. For pure fcc metals, the critical shear stress is low and insensitive to strain rate, for which slip systems are still active under high frequencies, thus the increase of frequency has little influence on them. For pure bcc metals, due to high dislocation activation energy and high critical shear stress, the slip systems tend to be suspended under high frequency, so the frequency effect is obvious. The frequency effect is also correlated with stress level and tends to show up at large plastic strain 


\begin{tabular}{|c|c|c|c|}
\hline \multicolumn{4}{|c|}{ Nomenclature } \\
\hline \multirow[t]{2}{*}{$2 a$} & \multirow{2}{*}{$\begin{array}{l}\text { fish-eye dimension in direction perpendicular to speci- } \\
\text { men surface }\end{array}$} & $r$ & inclusion radius \\
\hline & & $r_{p}$ & plastic zone size at crack tip \\
\hline \multirow{2}{*}{$\begin{array}{l}A \\
(\text { area })^{1 / 2} \\
2 b\end{array}$} & $\begin{array}{l}\mu /[(2 \pi(1-v)] \\
\text { the size of FGA or inclusion }\end{array}$ & $R_{1}$ & radius of fish-eye on fracture surface under ultrasonic \\
\hline & $\begin{array}{l}\text { fish-eye dimension in direction parallel to specimen } \\
\text { surface }\end{array}$ & $S$ & the standard deviation of the scatter \\
\hline & Deborah factor & $\tau$ & stress applied on dislocations \\
\hline & loading frequency & $\tau_{0}$ & stress required to give a dislocation velocity $v_{0}=1 \mathrm{~cm} / \mathrm{s}$ \\
\hline $\begin{array}{l}f \\
F_{I}^{M}\end{array}$ & correction factor of crack shape & $\Delta U$ & dimensionless unit increment of energy \\
\hline \multirow{2}{*}{$k$} & resistance of dislocation movement & $w_{i}$ & surface energy related to subsurface crack initiation \\
\hline & $w_{i} / w_{s}$ & $w_{s}$ & surface energy related to surface crack initiation \\
\hline $\begin{array}{l}k_{w} \\
\Delta K\end{array}$ & stress intensity factor & $\mu$ & shear modulus \\
\hline \multirow{3}{*}{$\begin{array}{l}\Delta K_{t h} \\
\Delta K_{t r}\end{array}$} & threshold value of $\Delta K$ for fatigue crack growth & $v$ & Poisson's ratio \\
\hline & value of $\Delta K$ at transition point from Paris law & $\Delta \sigma$ & applied stress amplitude \\
\hline & grain radius & $\sigma_{b}$ & ultimate tensile stress \\
\hline & dislocation moving distance & $\sigma_{w}$ & fatigue limit or fatigue strength at $N=10^{7}$ \\
\hline & fatigue failure cycles & $\Delta \sigma_{f s}$ & fatigue strength difference between $N=10^{7}$ and $N=10^{9}$ \\
\hline & fatigue cycles required for crack initiation at subsurface & $\varphi$ & $0.5 \Delta \sigma / k$ \\
\hline & fatigue cycles required for crack initiation at surface & $\psi$ & $r / l$ \\
\hline
\end{tabular}

amplitudes [15]. The loading frequency can change the fatigue mechanism of bcc metals. Under high frequencies, the dislocations are hardly to be activated and the fracture modes tend to transit from ductile to brittle. The behavior of hcp metals is very similar to bcc ones. Due to high dislocation activation energy, the frequency effect of hcp metals is also obvious. For most alloys, they have relatively higher strength and the dislocation movement is strongly impeded by interstitials, second phases and inclusions. In brief, the influence of frequency on the fatigue properties of metallic materials is rather complicated and till now has not any theoretical explanation been proposed. Therefore, the effect of loading frequency needs further investigation.

In the present study, fatigue testing of a high carbon chromium bearing steel ( $\mathrm{GCr} 15)$ quenched then tempered at four different temperatures, was performed with rotating bending and ultrasonic fatigue testing machines to clarify the effect of strength level and loading frequency on fatigue behavior.

\section{Experimental procedure}

\subsection{Material and specimens}

The material used in this investigation is a high carbon chromium bearing steel (GCr15). The chemical composition (mass percentage) of this steel is: $1.01 \mathrm{C}, 1.45 \mathrm{Cr}, 0.35 \mathrm{Mn}, 0.28 \mathrm{Si}, 0.015 \mathrm{P}$, $0.01 \mathrm{~S}$ and balance Fe. From the annealed steel bar, specimens were machined into hourglass shape with a certain amount of finishing margin. The specimens were heated at $845^{\circ} \mathrm{C}$ for $2 \mathrm{~h}$ in vacuum, then oil-quenched and tempered for $2.5 \mathrm{~h}$ in vacuum at $150{ }^{\circ} \mathrm{C}$, $300{ }^{\circ} \mathrm{C}, 450^{\circ} \mathrm{C}$ and $600^{\circ} \mathrm{C}$ with furnace-cooling, respectively. The final geometries of specimens are shown in Fig. 1. Before fatigue testing, the round notch surface was polished by the grade 400 , 800,1500 and 2000 abrasive papers.

Before fatigue testing, tensile testing was conducted on an MTS 810 system with cylindrical specimens of $6 \mathrm{~mm}$ in diameter at a strain rate of $10^{-4}$. Hardness measurement was performed using a Vickers hardness tester at a load of $50 \mathrm{~g}$ with the load holding time of $15 \mathrm{~s}$.

\subsection{Fatigue testing methods}

The conventional frequency fatigue test was performed at room temperature in air by using a four-axis cantilever-type rotating bending machine, which was operated at $3150 \mathrm{rpm}(f=52.5 \mathrm{~Hz})$, and the stress ratio was $R=-1$. The ultrasonic fatigue testing was conducted on a Shimadzu USF-2000 at a resonance frequency of $20 \mathrm{kHz}$ at room temperature in air, with a resonance interval of $100 \mathrm{~ms}$ per $500 \mathrm{~ms}$ and the stress ratio $R=-1$. Compressive air was used to cool the specimens during ultrasonic fatigue testing. After the fatigue testing, the fracture surfaces of all fractured specimens were examined by using a field-emission type scanning electron microscope (FE-SEM).

\section{Experimental results}

\subsection{Microstructure and mechanical properties}

The microstructure observations on etched specimen are shown in Fig. 2. Big residual spheroidal carbides are observed on the four groups of specimens. The number and size of cementite particles precipitated during tempering increased as tempering temperature increased. The microstructure of specimens tempered at $150{ }^{\circ} \mathrm{C}$ and $300{ }^{\circ} \mathrm{C}$ is tempered martensite. From SEM photographs, it is seen that small martensite blocks present, with the measured average lamellar width of $378 \mathrm{~nm}$. The carbon content in martensite is about $0.2 \%$ for specimens tempered at $150{ }^{\circ} \mathrm{C}$ and $0.06 \%$ for specimens tempered at $300{ }^{\circ} \mathrm{C}$. For specimens tempered at $450{ }^{\circ} \mathrm{C}$, the microstructure is troostite in which ferrite still has the shape of martensite and the carbon content in ferrite is lower than $0.02 \%$. When tempered at $600{ }^{\circ} \mathrm{C}$, recovery and recrystallization occurred in the ferrite matrix. The dislocation density and carbon content in ferrite decrease greatly.

The austenite grain size is about $13.8 \mu \mathrm{m}$, obtained from 1638 grains of intergranular fatigue fracture surface of specimens tempered at $150{ }^{\circ} \mathrm{C}$ and $300^{\circ} \mathrm{C}$. In the following text, T.T. is used for the abbreviation of tempering temperature, R.B. stands for rotating bending, and UL stands for ultrasonic loading.

Table 1 lists the mechanical properties of the four groups of specimens. It is seen that the ultimate tensile strength decreases as the tempering temperature increases.

\section{2. $S-N$ curves}

Fig. 3 presents the $S-N$ curves for the four groups of specimens tested in rotating bending and ultrasonic fatigue testing. It is noted that for specimens with the highest strength (T.T. $150{ }^{\circ} \mathrm{C}$ ) the 


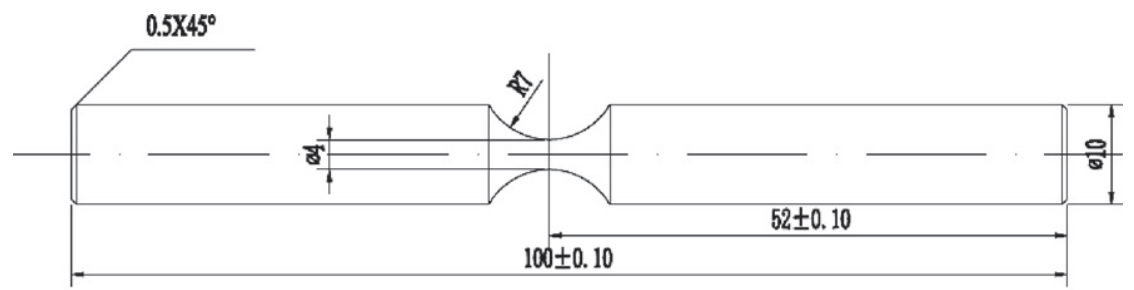

(a) For rotating bending fatigue

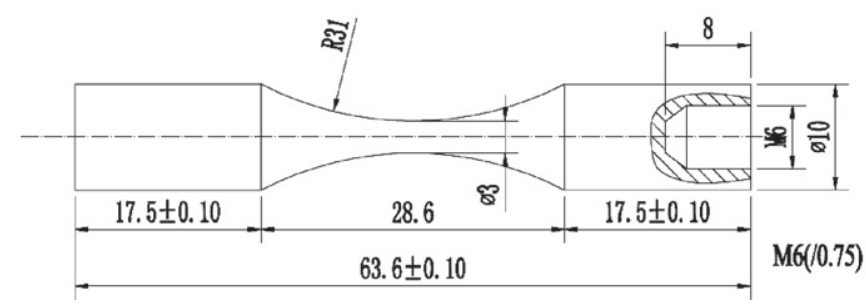

(b) For ultrasonic fatigue

Fig. 1. Shapes and dimensions (in $\mathrm{mm}$ ) of specimens for fatigue tests.

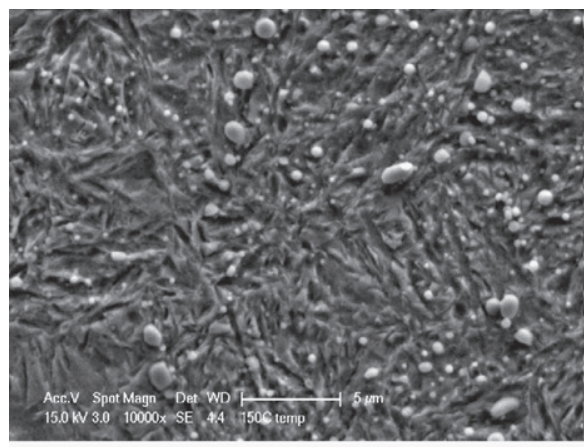

(a) $150^{\circ} \mathrm{C}$

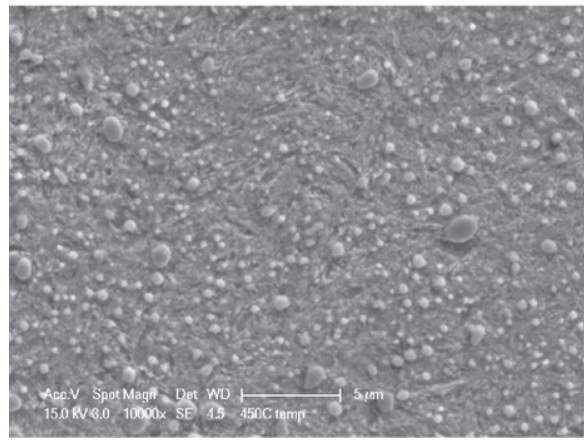

(c) $450^{\circ} \mathrm{C}$

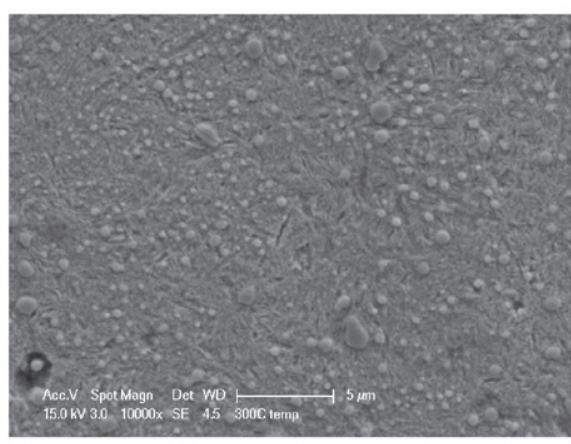

(b) $300^{\circ} \mathrm{C}$

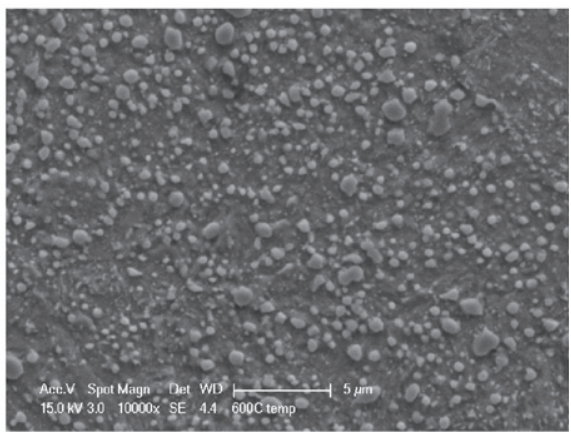

(d) $600^{\circ} \mathrm{C}$

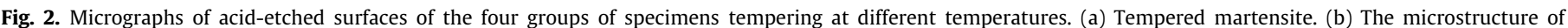

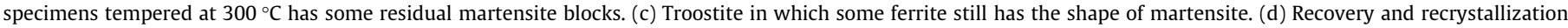
occurred in the ferrite matrix for specimens tempered at $600{ }^{\circ} \mathrm{C}$.

Table 1

Mechanical properties of four groups of specimens.

\begin{tabular}{llll}
\hline Tempering temp. $\left({ }^{\circ} \mathrm{C}\right)$ & Micro-hardness Hv $\left(\mathrm{kgf} / \mathrm{mm}^{2}\right)$ & \multicolumn{2}{l}{ Tensile test (MPa) } \\
\cline { 3 - 4 } & & $\sigma_{y}$ & $\sigma_{b}$ \\
\hline 150 & 820 & NA & 2372 \\
300 & 741 & 2000 & 2150 \\
450 & 524 & 1537 & 1677 \\
600 & 327 & 909 & 1044 \\
\hline
\end{tabular}

fatigue strength is a little higher under ultrasonic loading. While for the other three groups of specimens, fatigue resistance under ultrasonic loading is markedly higher than that under conventional frequency loading.

The $S-N$ curve of specimen T.T. $150{ }^{\circ} \mathrm{C}$ presents a continuously descending shape in rotating bending and ultrasonic fatigue testing, although stepwise $S-N$ curves or duplex curves were mostly reported in rotating bending fatigue testing [4,21-24]. For specimens T.T. $300^{\circ} \mathrm{C}$ and T.T. $450^{\circ} \mathrm{C}$, the $S-N$ curves show a continuously 

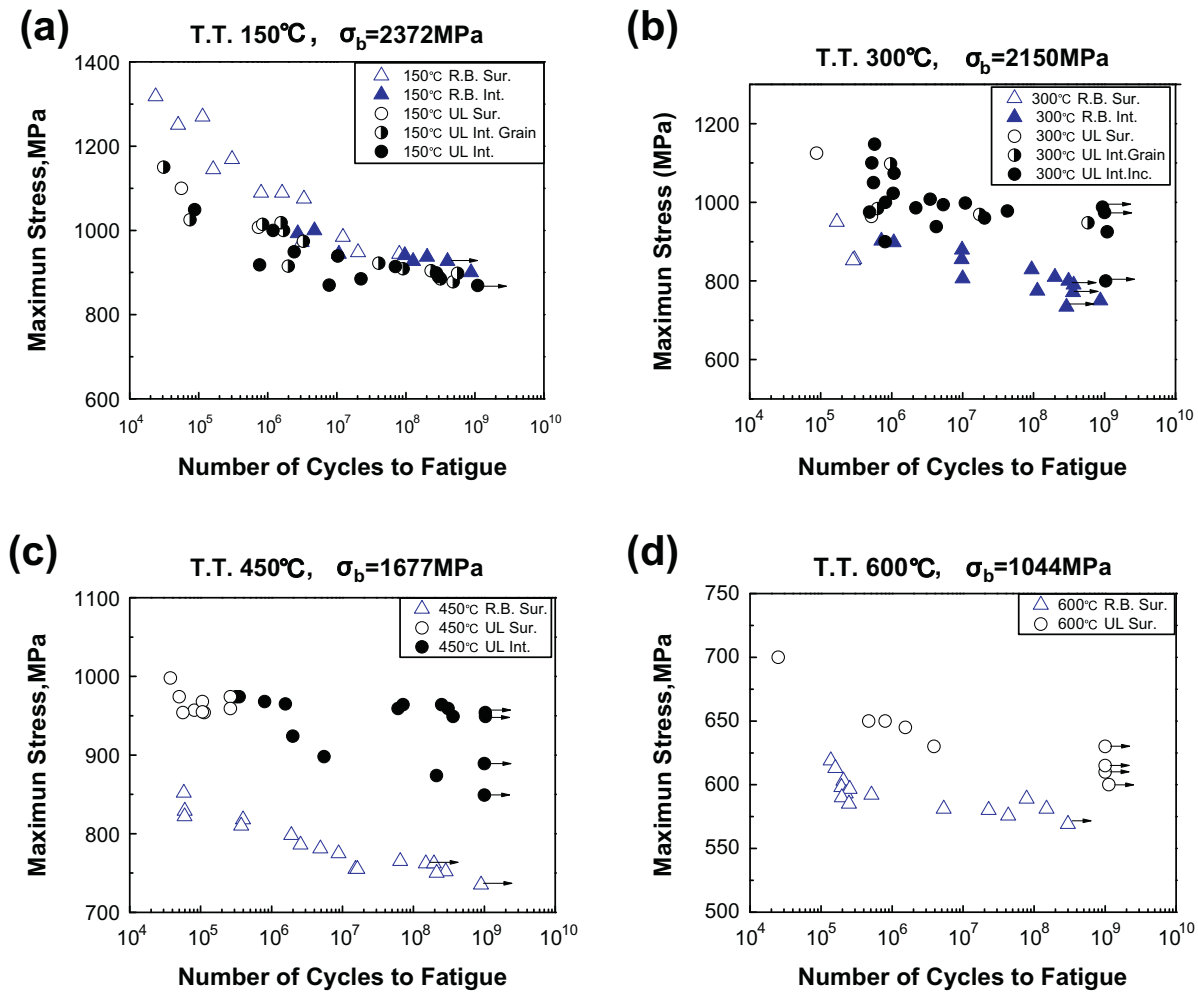

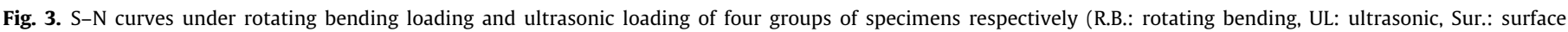
initiation, Int.: interior initiation, T.T.: tempering temperature. Symbol with arrow: no broken.).

descending shape under rotating bending loading, but it turns out to be a horizontal asymptote shape under ultrasonic loading. For specimens T.T. $600^{\circ} \mathrm{C}$, both $S-N$ curves present a horizontal asymptote shape and clearly have a fatigue limit.

\subsection{Fractography}

The typical patterns of interior-initiated fracture surface in rotating bending and ultrasonic fatigue testing are shown in Fig. 4. The whole region of crack initiation and early propagation exhibits a pattern of "fish-eye", and a relatively rough region with fine granular morphology often presents surround the inclusion inside fish-eye, which is so-called "fine granular area" (FGA) [24]. Region A outside fish-eye displays an intergranular/transgranular morphology, and this kind of morphology is only observed in specimens T.T. $150{ }^{\circ} \mathrm{C}$ and T.T. $300^{\circ} \mathrm{C}$. Region B displays a radioactive morphology indicating fast crack growth. The schematic representation of fatigue facture surface is shown in Fig. 4e.

For specimens T.T. $150{ }^{\circ} \mathrm{C}$ and T.T. $300{ }^{\circ} \mathrm{C}$, crack initiates from surface in low cycle regime, as shown in Fig. 5a. In high cycle regime, crack initiates from the internal defects of specimen showing a fish-eye pattern without FGA, as shown in Fig. 5b. And in very high cycle regime, FGA is easily observed surrounding the internal defects inside fish-eye, as shown in Fig. 5c. Internal grain boundary induced failure is also observed, as shown in Fig. $5 \mathrm{~d}$.

Fig. 6 shows the fractography of specimens T.T. $450{ }^{\circ} \mathrm{C}$ and T.T. $600{ }^{\circ} \mathrm{C}$. It is noted that, for specimens T.T. $450{ }^{\circ} \mathrm{C}$, all the specimens failed from surface in rotating bending testing as shown in Fig. $6 a$. Under ultrasonic loading, fatigue crack still initiates from internal defects in VHCF regime as shown in Fig. 6b, but FGA is hardly to be observed. The fractography of specimens T.T. $600^{\circ} \mathrm{C}$ is shown in Fig. $6 \mathrm{c}$ and d. All specimens failed from surface under two loading cases.

\section{Discussion}

\subsection{Quantitative evaluation of crack initiation site}

The values of $(\text { area })^{1 / 2}$ are calculated for the sizes of inclusion and FGA for each specimen. These results are plotted as a function of the fatigue life as shown in Fig. 7a and b. It is noted that the size of FGA (area $)_{F G A}^{1 / 2}$ increases with the increase of fatigue life, while the size of inclusion (area) $)_{\text {Inc }}^{1 / 2}$ is less relevant to fatigue life. From Fig. 7c, it is seen that the size of FGA (area $)_{F G A}^{1 / 2}$ increases with that of inclusion (area $)_{\text {Inc. }}^{1 / 2}$ and Fig. $7 d$ shows that the depth of inclusion does not affect the fatigue life obviously. This is in agreement with the results in the literature [21,25-28].

The range of stress intensity factor (SIF) at the front of inclusion and FGA, $\Delta K_{\text {ini, }}$, is calculated by using the following equation [29]:

$\Delta K_{\text {ini }}=0.5 \Delta \sigma_{a} \sqrt{\pi \sqrt{\text { area }_{\text {ini }}}}$

where $\Delta \sigma_{a}$ is the local stress amplitude at the center of inclusion or FGA. For surface inclusion, 0.65 is used for the coefficient in Eq. (1) instead of 0.5 . The results are plotted as a function of fatigue life as shown in Fig. 8a. It is noted that the value of $\Delta K$ of inclusions tends to decrease as fatigue life increases, while that of FGA keeps almost a constant regardless of fatigue life, loading frequencies and tempering temperatures, which is about $5.2 \mathrm{MPa} \mathrm{m}^{1 / 2}$.

As illustrated in Fig. 4, the fracture surface of specimen is divided into several typical regions. Here the intergranular/transgranular region is discussed. Under rotating bending loading, the value of $\Delta K$ at the deepest site of the semi-circular where the region begins is calculated as follows:

$\Delta K_{\mathrm{I}}=\Delta \sigma \sqrt{\pi a} F_{\mathrm{I}}^{M}$

where $F_{I}^{M}$ is the correction factor depending on the geometry of specimen and crack, and it is available in the handbook [30]. Under 


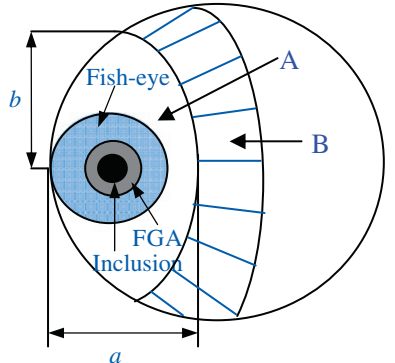

(a)

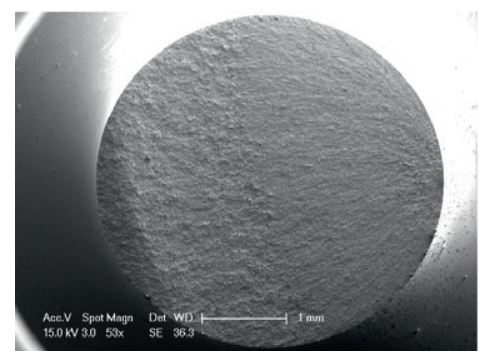

(c)

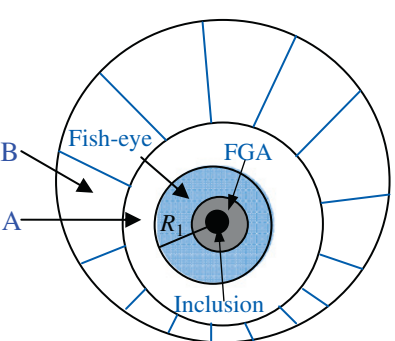

(b)

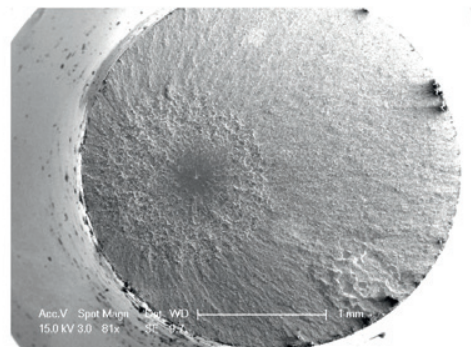

(d)

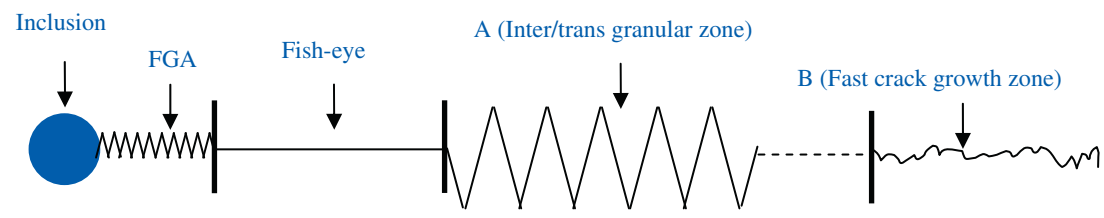

(e)

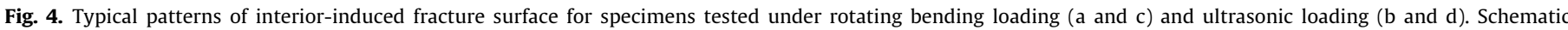
representation of morphology is shown in (e).

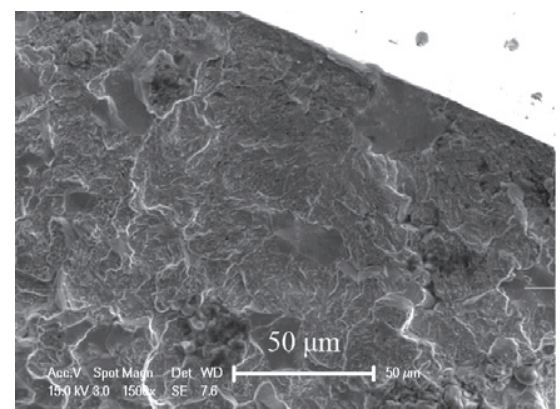

(a) $\sigma=1089 \mathrm{MPa}, N_{f}=7.978 \times 10^{5}$

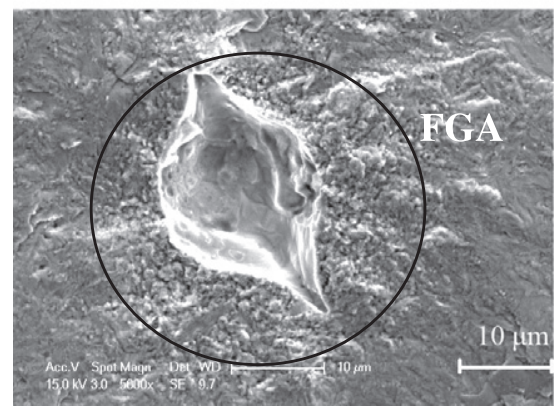

(c) $\sigma=890 \mathrm{MPa}, N_{f}=2.97 \times 10^{8}$

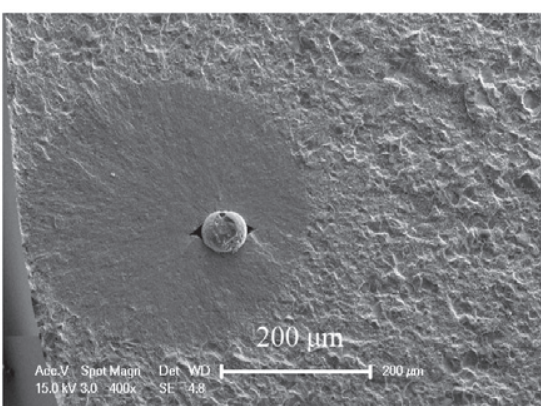

(b) $\sigma=806 \mathrm{MPa}, N_{f}=9.99 \times 10^{6}$

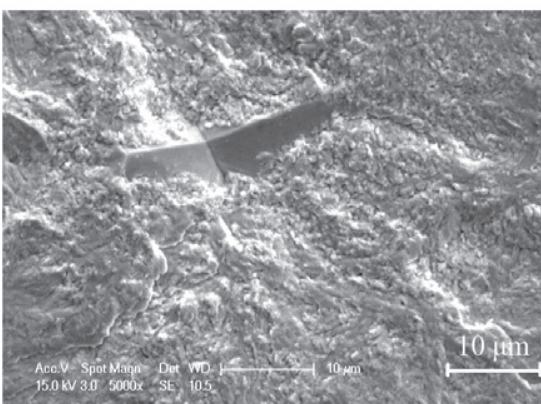

(d) $\sigma=909 \mathrm{MPa}, N_{f}=9.125 \times 10^{7}$

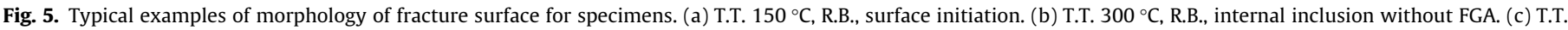
$150^{\circ} \mathrm{C}$, UL, internal inclusion with FGA. (d) T.T. $150^{\circ} \mathrm{C}$, UL, internal grain boundary. 


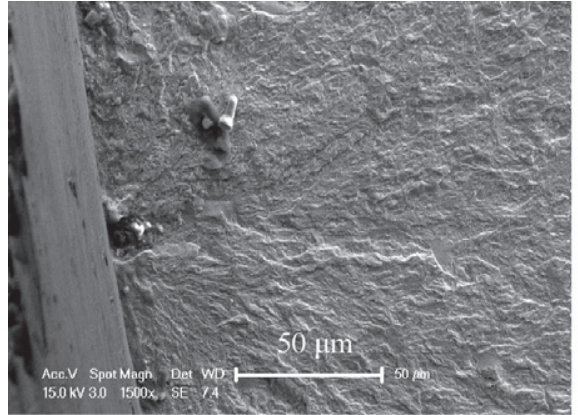

(a) $\sigma=765 \mathrm{MPa}, N_{f}=6.542 \times 10^{7}$

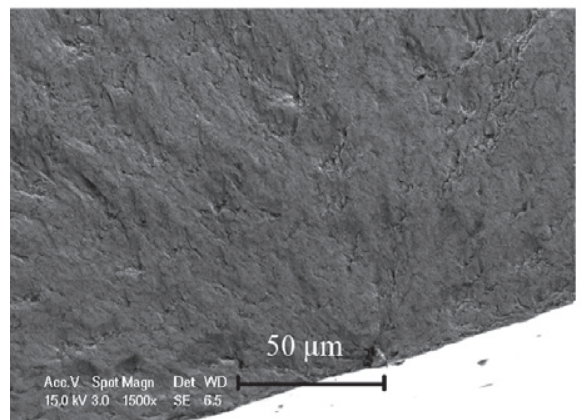

(c) $\sigma=580 \mathrm{MPa}, N_{f}=2.218 \times 10^{7}$

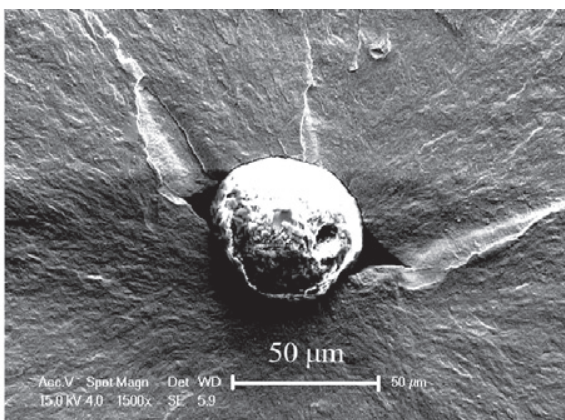

(b) $\sigma=874 \mathrm{MPa}, N_{f}=2.116 \times 10^{8}$

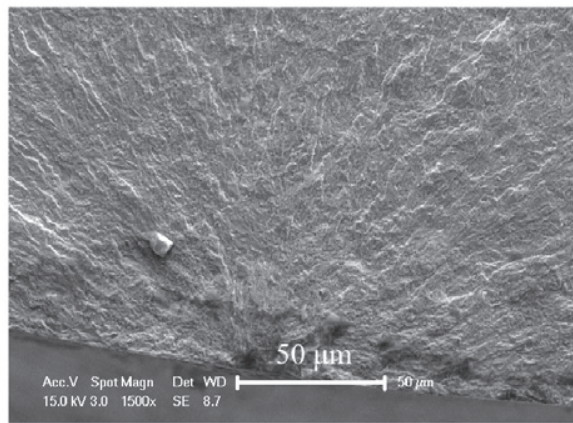

(d) $\sigma=650 \mathrm{MPa}, N_{f}=8 \times 10^{5}$

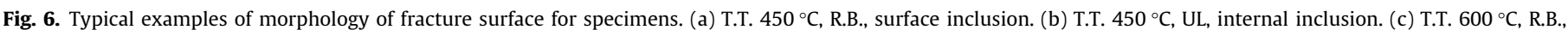
surface slip. (d) T.T. $600{ }^{\circ} \mathrm{C}$, UL, surface inclusion.

(a)

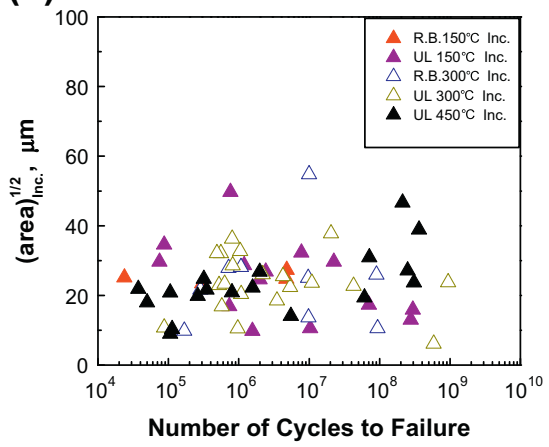

(c)

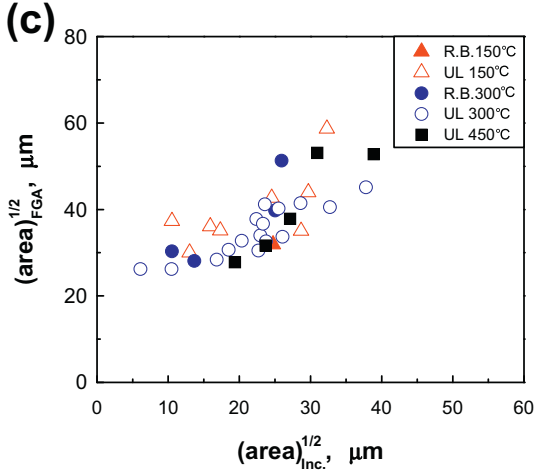

(b)

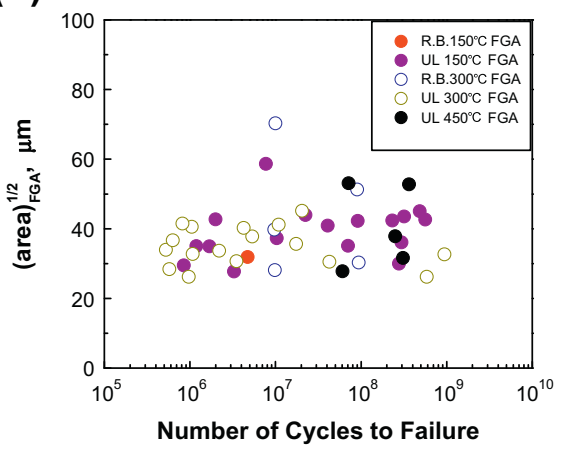

(d)

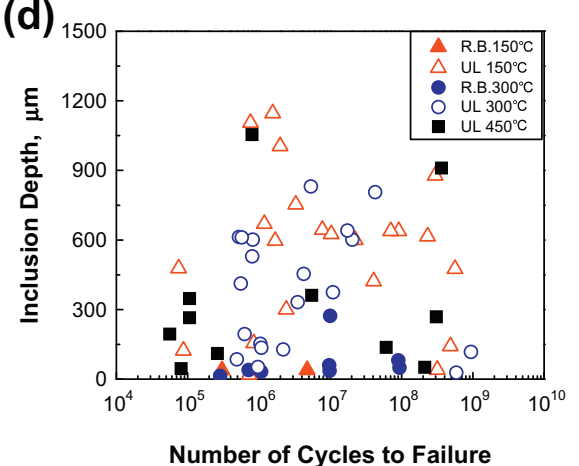

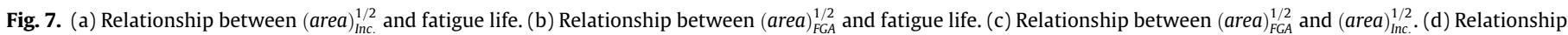
between inclusion depth and fatigue life. 
(a)

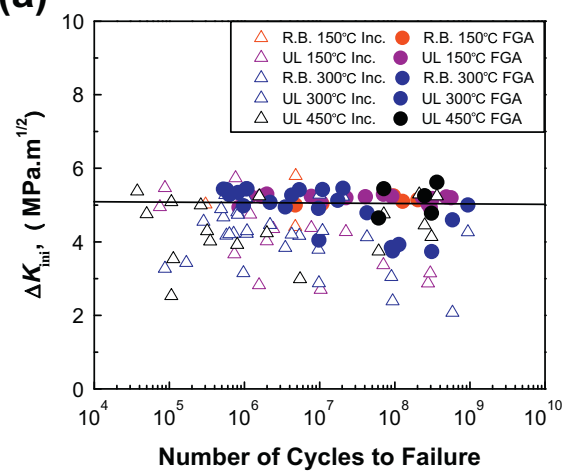

(b)

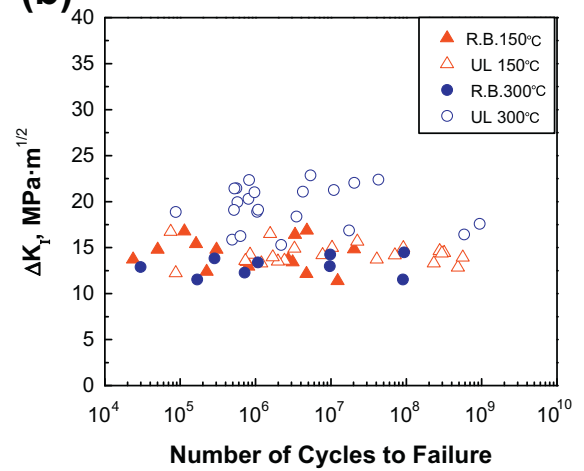

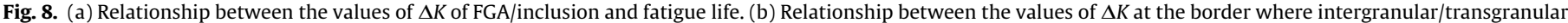
region begins and fatigue life.

ultrasonic loading, the value of $\Delta K$ at the border where the intergranular/transgranular region begins (the circular area with a radius of $R_{1}$, a region similar to fish-eye) is calculated as follows:

$\Delta K_{\mathrm{I}}=\frac{2}{\pi} \Delta \sigma \sqrt{\pi R_{1}}$

The result is shown in Fig. 8b. It is seen that the values of $\Delta K_{I}$ keep almost constant around $15 \mathrm{MPa} \mathrm{m}^{1 / 2}$ for specimens T.T. $150{ }^{\circ} \mathrm{C}$ under two loading styles and for specimens T.T. $300{ }^{\circ} \mathrm{C}$ under rotating bending loading. But the values of $\Delta K_{I}$ for specimen T.T. $300{ }^{\circ} \mathrm{C}$ under ultrasonic loading are relatively larger. The reason why the values change so much needs further investigation.

The studies on a similar bearing steel (JIS SUJ2) by Sakai [31]. reported that the threshold value of $\Delta K$ for crack propagation, $\Delta K_{t h}$, is assumed to be $5 \mathrm{MPa} \mathrm{m}^{1 / 2}$, which is close to $\Delta K_{F G A}$. The transition point from Paris law, $\Delta K_{t r}$, is suggested to be about $14 \mathrm{MPa} \mathrm{m}^{1 / 2}$, and it is close to the value of $\Delta K$ calculated at the border of the intergranular/transgranular region, $\Delta K_{I S}$. Thus:

$\Delta K_{F G A} \cong \Delta K_{t h}$

$\Delta K_{I S} \cong \Delta K_{\text {tr }}$

A parallel investigation by the present authors [32] revealed that the plastic zone size $r_{p}$ at the front of FGA and fish-eye are $220 \mathrm{~nm}$ and $12 \mu \mathrm{m}$, which are close to two material characteristic sizes in GCr15: the width of martensite lamellar (378 nm) and the prior austenite grain size $(13.8 \mu \mathrm{m})$. Thus, the morphology evolution from FGA to fish-eye and to intergranular/transgranular area is caused by the change of plastic zone size at the crack front with the relation to material characteristic sizes.

\subsection{Effect of strength level and loading frequency on fatigue resistance of materials}

The values of fatigue strength at $N=10^{6}, 10^{7}, 10^{8}$ and $10^{9}$ are shown in Fig. 9. Under rotating bending, the fatigue strength decreases as tensile strength decreases at any specified fatigue life. The difference between the fatigue strength at $N=10^{7}$ and $N=10^{9}$ (extrapolated) is relatively larger when the tensile strength is higher. For specimens with tensile strength higher than $2000 \mathrm{MPa}$ (T.T. $150{ }^{\circ} \mathrm{C}, 2372 \mathrm{MPa}$ and T.T. $300^{\circ} \mathrm{C}, 2150 \mathrm{MPa}$ ), the difference is up to $65 \mathrm{MPa}$ and $115 \mathrm{MPa}$, which is larger than the other two specimen groups with lower strength. For specimens T.T. $450{ }^{\circ} \mathrm{C}$ $(1677 \mathrm{MPa})$ and T.T. $600{ }^{\circ} \mathrm{C}(1044 \mathrm{MPa})$, the decrease is $40 \mathrm{MPa}$ and $10 \mathrm{MPa}$. However, there is distinct difference under ultrasonic loading. Fig. 9b shows that the fatigue strength of specimens at any specified fatigue life does not change too much in the VHCF regime except for the specimens with the lowest strength.

The ratio of fatigue limit to tensile strength increases as the tensile strength decreases under both loading cases as shown in Fig. 9c. Experiments of a similar material (NF 100C6) with tempering temperature of $180^{\circ} \mathrm{C}$ (tensile strength: $2300 \mathrm{MPa}$ ) were reported by Marines et al. at two different loading frequencies [1]. The experiments show no difference at different loading frequencies and the results are included in Fig. 9c for comparison. It is noted that for specimens T.T. $150{ }^{\circ} \mathrm{C}$, fatigue strength under ultrasonic loading is a little lower than that under rotating bending loading. For specimens T.T. $180^{\circ} \mathrm{C}$, fatigue strength under two loading frequencies is almost the same. For specimens T.T. $300{ }^{\circ} \mathrm{C}$, T.T. $450^{\circ} \mathrm{C}$ and T.T. $600^{\circ} \mathrm{C}$, fatigue strength is markedly higher under ultrasonic loading. It is suggested that loading frequencies do have effect on fatigue behavior of materials, but for materials with different microstructure, the resultant of the effect may defer.

A group of data on fatigue strength of low alloy steels is collected by the authors and the results are shown in Fig. 10 [33]. The data were cited from 32 papers, including 58 material cases. Fig. 10a shows that $\sigma_{w}$ increases with $\sigma_{b}$, i.e. $\sigma_{w}=0.468 \sigma_{b}$. Fig. $10 \mathrm{~b}$ shows that the fatigue strength difference between $10^{7}$ and $10^{9}$ is larger than $50 \mathrm{MPa}$ frequently in high tensile strength cases, with the largest value around $200 \mathrm{MPa}$. In low strength cases, the difference is small. The data of present work are also presented for comparison.

In VHCF regime, although the material is macroscopically elastic, local micro-plasticity caused by very small irreversible cyclic slips may still occur in some regions and accumulates to final failure [34]. Most damage occurs at the maximum load in a cycle. Hence a slower strain rate, or a longer time at maximum load is more detrimental. In some papers, the damping heat in fatigue process was measured by micro-thermocouples or infrared camera to calculate the plastic strain amplitude [35-37]. It was found that, at the same stress level, the equivalent plastic strain amplitude at $f=100 \mathrm{~Hz}$ was one or two magnitudes larger than that under ultrasonic loading. This may explain why the fatigue strength is generally higher at ultrasonic than that at low frequencies and applies to the specimens with lower strength (T.T. $300^{\circ} \mathrm{C}$, T.T. $450^{\circ} \mathrm{C}$ and T.T. $600^{\circ} \mathrm{C}$ ). But for specimens with the highest strength (T.T. $150^{\circ} \mathrm{C}$ and T.T. $180^{\circ} \mathrm{C}$ ), the influence of frequency is small. Other studies were carried out on cast iron by Wang et al. [9], and on spring steels by Furuya et al. [5] and Marines et al. [16], which came out with similar results. It is suggested that loading frequencies have little influences on brittle materials with low plasticity. 
(a)

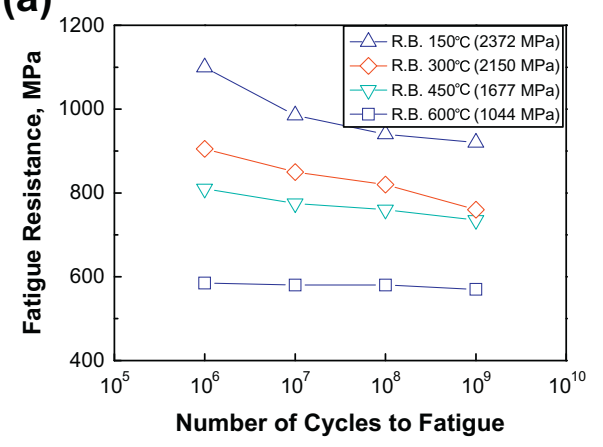

(b)

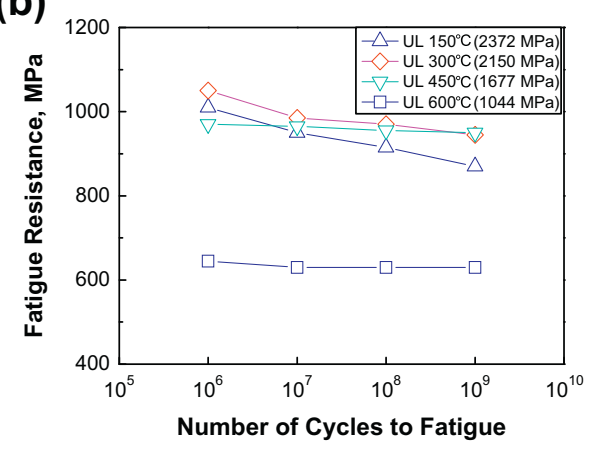

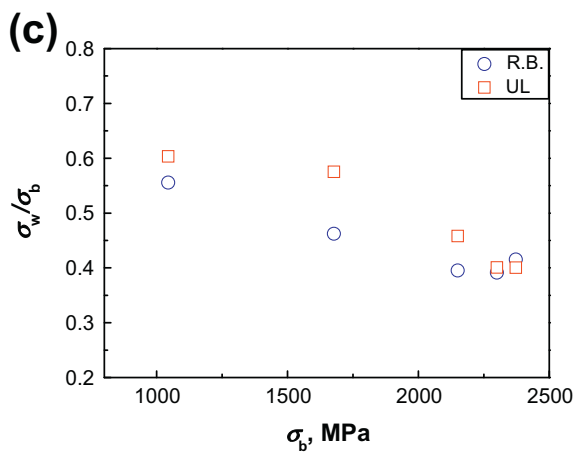

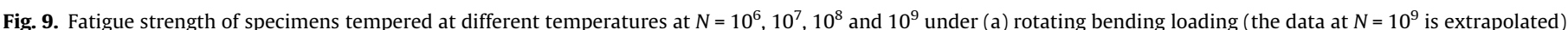

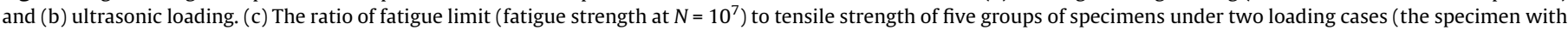
a tensile strength of $2300 \mathrm{MPa}$ is NF 100C6, while the other four groups of specimens are the materials used in this paper).
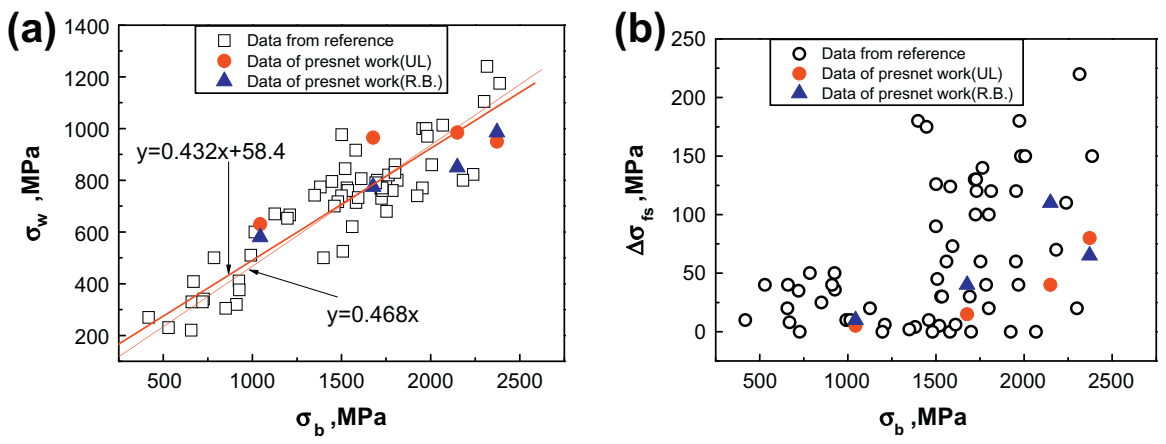

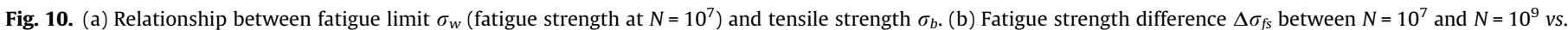
tensile strength $\sigma_{b}$

\subsection{Effect of strength level and loading frequency on $S-N$ curve characteristics}

Fig. 11 schematizes typical $S-N$ curves for carbon steels and low-alloy steels. For low-strength steels, the $S-N$ curve is of a horizontal asymptote shape and clearly has a fatigue limit as line 1 shown in Fig. 11. For high-strength steels, step-wise curves or duplex curves are mostly reported in the literatures (line (2)) and there is no fatigue limit. $S-N$ curves exhibiting a continuously descending shape are also reported (line (3)). It is noted that as material strength increases, fatigue limit disappears and the $S-N$ curve continues to descend. For specimens with the lowest tensile strength (T.T. $600{ }^{\circ} \mathrm{C}, 1044 \mathrm{MPa}$ ), the $S-N$ curve resembles line (1). For specimens with the highest tensile strength (T.T. $150{ }^{\circ} \mathrm{C}$, $2372 \mathrm{MPa}$ ), the $S-N$ curve resembles line (3). For the other two groups of specimens (T.T. $300^{\circ} \mathrm{C}, 2150 \mathrm{MPa}$ and T.T. $450{ }^{\circ} \mathrm{C}$, $1677 \mathrm{MPa}$ ), the $S-N$ curves resemble line (3) in rotating bending testing and line (1) in ultrasonic testing which presents a fatigue limit.
Generally, in low-strength steels only surface fatigue failure mode exists and the plateau of line (1) corresponds to surface fatigue limit. But in high-strength steels internal fatigue failure mode occurs in VHCF regime, thus the $S-N$ curve will continue to descend. A plateau as shown in line (2) will appear when the probability of surface crack initiation equals to internal crack initiation, and in the plateau region, the scatter of data is evident.

\subsection{Effect of strength level and loading frequency on transition of fatigue crack initiation site}

The tensile strength has a substantial effect on the fatigue crack initiation site. It is noted from Figs. 3, 5 and 6 that the specimens with the lowest tensile strength (T.T. $600^{\circ} \mathrm{C}, 1044 \mathrm{MPa}$ ) show only surface-induced crack initiation under two loading cases, while for specimens with higher tensile strength (T.T. $150^{\circ} \mathrm{C}, 2372 \mathrm{MPa}$ and T.T. $300^{\circ} \mathrm{C}, 2150 \mathrm{MPa}$ ), cracks initiate from subsurface in VHCF regime. For specimens with medium strength (T.T. $450^{\circ} \mathrm{C}$, $1677 \mathrm{MPa})$, cracks all initiate from surface in rotating bending 


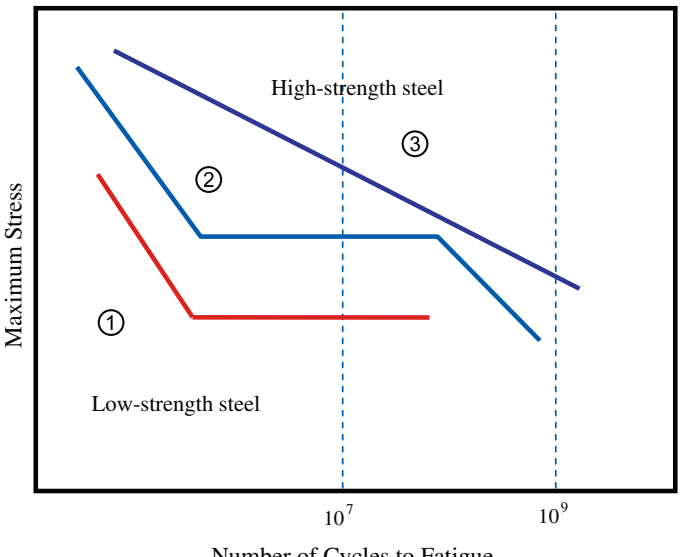

Number of Cycles to Fatigue

Fig. 11. Schematics of typical $S-N$ curves for carbon and low-alloy steels. The $S-N$ curve of low-strength steels is of a horizontal asymptote shape as line (1) and clearly has a fatigue limit. The $S-N$ curve of high-strength steels is of a step-wise shape as line (2) or a continuously descending shape as line (3) and there is no sign of fatigue limit.

testing, whereas in ultrasonic testing, crack initiates from subsurface in VHCF regime. But there is no obvious difference in fractography morphology, and the transition of crack initiation site is more likely to be caused by the difference of loading style. Thus, it is suggested that as material strength increases crack tends to initiate from subsurface while loading frequency has little effect on crack initiation site.

A review article [33] has shown that with larger tensile strength, there is a tendency for crack to initiate from subsurface. In order to interpret the mechanism of fatigue crack initiation either at surface or at subsurface, a new parameter $D^{*}$ is proposed elsewhere $[38,39]$ for this regard:

$D^{*}=\frac{N_{i}}{N_{s}}=\frac{1.25 k_{w}(\varphi-1)^{2}}{\Delta \tilde{U} \psi^{2}}$

where $N_{i}$ is the number of cycles for subsurface crack initiation and $N_{s}$ is the number of cycles for surface crack initiation. When $N_{s}<N_{i}$, i.e. $D^{*}>1$, crack originates at surface. When $D^{*}<1$, crack originates at subsurface. $k_{w}$ is the ratio of surface energy related to crack initiation at surface and subsurface. In dry air, $k_{w} \approx 1 . \Delta \tilde{U}$ is the dimensionless unit increment of energy for dislocations in cycling. $\psi=r / l$ is the ratio of inclusion radius $(r)$ to grain radius $(l) . \varphi=\Delta \sigma / 2 k$ is the ratio of stress amplitude $(\Delta \sigma)$ to the resistance of dislocation movement $(k)$.

Simulation results [39] showed that $D^{*}$ decreases as $\varphi$ and $\psi$ decrease, i.e. at relatively low cyclic loading level, high strength of material, large inclusion size and small grain size, fatigue crack tends to initiate at subsurface. Our present experimental results have verified that as material strength upgrades, crack tends to initiate at subsurface in VHCF regime.

\subsection{Explanation on effect of strength level and loading frequency in terms of dislocation movement}

A qualitative calculation is carried out to explain the effect of strength level and loading frequency. The velocity of a dislocation is expressed as [40]:

$v=v_{0}\left(\frac{\tau}{\tau_{0}}\right)^{m}, \quad v_{0}=1 \mathrm{~cm} / \mathrm{s}$

where $\tau$ is the shear stress on individual dislocations, $m$ is a material constant, and $\tau_{0}$ is a material constant representing the stress
Table 2

Dislocation moving distance with different values of $m$ at $\tau / \tau_{0}=1.1$

\begin{tabular}{lllllll}
\hline$m(\mu \mathrm{m})$ & 40 & 35 & 30 & 20 & 10 & 5 \\
\hline$L_{\mathrm{UL}}$ & 0.72 & 0.45 & 0.32 & 0.15 & 0.079 & 0.068 \\
$L_{\mathrm{RB}}$ & 274 & 170 & 120 & 55 & 30 & 26 \\
\hline
\end{tabular}

Table 3

Dislocation moving distance with different values of $m$ at $\tau / \tau_{0}=1.01$.

\begin{tabular}{lllllrr}
\hline$m(\mu \mathrm{m})$ & 40 & 35 & 30 & 20 & \multicolumn{1}{l}{10} & \multicolumn{1}{l}{5} \\
\hline$L_{\mathrm{UL}}$ & 0.024 & 0.023 & 0.025 & 0.027 & 0.034 & 0.044 \\
$L_{\mathrm{RB}}$ & 9.014 & 8.570 & 9.270 & 9.975 & 12.779 & 16.962 \\
\hline
\end{tabular}

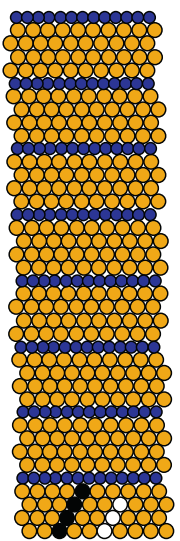

T.T. $150^{\circ} \mathrm{C}$

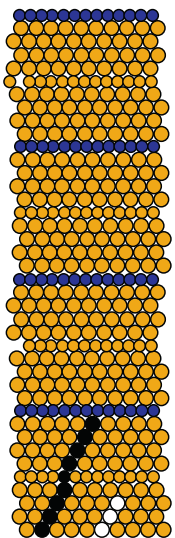

T.T. $300^{\circ} \mathrm{C}$

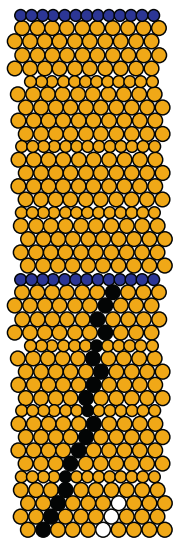

T.T. $450^{\circ} \mathrm{C}$

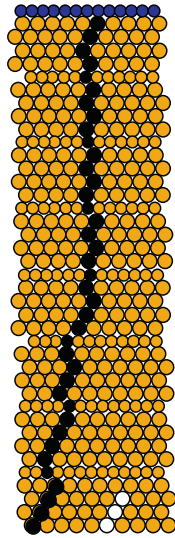

T.T. $600^{\circ} \mathrm{C}$
Fig. 12. Schematic representation of dislocation movement in specimens tempered at different temperatures. The orange circle represents Fe atom, relatively smaller blue circle represents Carbon atom, black circle represents the dislocation moving distance under rotating bending testing and white circle represents the distance under ultrasonic testing.

required to give a dislocation velocity $v_{0}=1 \mathrm{~cm} / \mathrm{s}$. The distance a dislocation travels in a quarter of cycle is:

$\begin{aligned} L & =\int_{0}^{T / 4} v \mathrm{~d} t=\int_{0}^{T / 4} v_{0}\left(\frac{\tau}{\tau_{0}} \sin (2 \pi f t)\right)^{m} \mathrm{~d} t \\ & =v_{0}\left(\frac{\tau}{\tau_{0}}\right)^{m} \int_{0}^{T / 4}(\sin (2 \pi f t))^{m} \mathrm{~d} t\end{aligned}$

Assuming $x=2 \pi f t$, thus:

$L=v_{0}\left(\frac{\tau}{\tau_{0}}\right)^{m} \frac{1}{2 \pi f} \int_{0}^{\pi / 2}(\sin x)^{m} \mathrm{~d} x \propto \frac{1}{f}$

Assuming $\tau / \tau_{0}=1.1$ and $\tau / \tau_{0}=1.01$, the moving distance of a dislocation is shown in Tables 2 and 3. It is noted that the moving distance in rotating bending testing $\left(L_{\mathrm{RB}}\right)$ is two orders of magnitude larger than that in ultrasonic testing $\left(L_{\mathrm{UL}}\right)$.

The calculation is taken under the assumption that dislocations move freely. Practically there are many obstacles in materials and they will shorten the moving distance markedly. In the present investigation, specimens are tempered at different temperatures and the amount of carbon atoms dissolved in matrix will decrease as tempering temperature increases. Thus the ability to impede the movability of dislocations is different. A schematic representation is shown in Fig. 12. The orange ${ }^{1}$ circles represent Fe atoms, rela-

\footnotetext{
${ }^{1}$ For interpretation of color in Figs. 3, 4, 7-12, the reader is referred to the web version of this article.
} 
tively smaller blue circles represent carbon atoms, black circles represent the dislocation moving distance in rotating bending testing and white circles represent the distance in ultrasonic testing. The dislocations will travel the same distance provided the same stress amplitude is given.

Under rotating bending, dislocations travel relatively longer distance and are all impeded by carton atom layers, i.e. the dislocation moving distance is restricted by carbon atom layers and the damage caused under the same stress increases as tempering temperature increases. And shown by the experiments, fatigue resistance decreases markedly as material strength decreases. Under ultrasonic loading, dislocation moving distance is relatively shorter and does not reach the obstacles which are mainly the carbon atom layers. Thus the damage caused by the same stress is the same for specimens tempered at different temperatures. And the experiments have shown that the difference of fatigue resistance for the three groups of specimens with higher tensile strength is small.

For specimens with the highest tensile strength (T.T. $150{ }^{\circ} \mathrm{C}$, $2372 \mathrm{MPa}$ ), the density of carbon atoms is high and the interval between obstacles is small. Thus the actual dislocation moving distance under different frequencies is almost the same and the difference of fatigue resistance is small. For the other specimens, the dislocation moving distance under ultrasonic loading is much smaller than that under rotating bending and fatigue resistance is much higher under ultrasonic loading. For materials reported with no frequency effect such as NF 100C6, JIS-SNCM439 and JISSUP7/SUP12 $[1,5,9]$, they are all tempered at low temperatures and the Carbon contents are high in martensite. Thus the frequency effect is substantially diminishing.

\section{Conclusions}

In the present investigation, fatigue testing of a high carbon chromium bearing steel ( $\mathrm{GCr} 15)$ quenched then tempered at four different temperatures $\left(150^{\circ} \mathrm{C}, 300^{\circ} \mathrm{C}, 450^{\circ} \mathrm{C}\right.$ and $\left.600{ }^{\circ} \mathrm{C}\right)$, was performed with rotating bending and ultrasonic fatigue testing machines. The following conclusions are dawn:

(1) As tensile strength increases, the fatigue strength of material increases and the crack initiation site tends to transit from surface to subsurface. Specimens with higher strength (T.T. $150{ }^{\circ} \mathrm{C}$ and T.T. $300^{\circ} \mathrm{C}$ ) failed from interior of specimen in VHCF regime, whereas specimens with lower strength (T.T. $450{ }^{\circ} \mathrm{C}$, T.T. $600^{\circ} \mathrm{C}$ ) showed only surface failure mode. For specimens with higher strength, the $S-N$ curves exhibit a continuously descending shape and the fatigue strength decrement between $N=10^{7}$ and $N=10^{9}$ is obvious. For lowstrength specimens, the $S-N$ curve is of a horizontal asymptote shape and has a fatigue limit. The internal fatigue fracture mode in high-strength specimens is the main reason for the descending in VHCF regime.

(2) Loading frequencies do have effect on fatigue strength of materials, but for materials with some specific microstructure the resultant of the effect may defer. The experiments show that loading frequencies have little influence on specimens with the highest strength (T.T. $150^{\circ} \mathrm{C}$ ), while for the other specimens with lower tensile strength the fatigue resistance is markedly high in ultrasonic testing. Loading frequencies do not change the failure mode of specimens, i.e. loading frequencies have no effect on the transition of fatigue crack initiation site.

(3) An explanation on the effect of strength level and loading frequency is proposed in terms of dislocation movement. It is suggested that the dislocations travel shorter distance at higher loading frequency than that at lower frequency provided the same stress is given, thus the accumulated damage is smaller and the fatigue resistance is higher. But for materials with obstacles dense enough to impede dislocation movement, the influence of frequency is substantially diminishing.

\section{Acknowledgments}

This paper was supported by the National Natural Science Foundation of China (Nos. 10772178 and 11172304) and the Knowledge Innovation Program of the Chinese Academy of Sciences (No. KJCX2-YW-L07).

\section{References}

[1] Marines I, Bin X, Bathias C. An understanding of very high cycle fatigue of metals. Int J Fatigue 2003;25(9-11):1101-7.

[2] Natio T, Ueda H, Kikuchi M. Fatigue behavior of carburized steel with internal oxides and nonmartensitic near the surface. Metall Trans A 1984;15(7):1431-6

[3] Miller KJ, O'Donnell WJ. The fatigue limit and its elimination. Fatigue Fract Eng Mater Struct 1999;22(7):545-57.

[4] Murakami Y, Nomoto T, Ueda T. Factors influencing the mechanism of superlong fatigue failure in steels. Fatigue Fract Eng Mater Struct 1999;22(7):581-90.

[5] Furuya Y, Matsuoka S, Abe T, Yamaguchi K. Gigacycle fatigue properties for high-strength low-alloy steel at $100 \mathrm{~Hz}, 600 \mathrm{~Hz}$, and $20 \mathrm{kHz}$. Scripta Mater 2002;46(2):157-62.

[6] Furuya Y, Matsuoka S. Improvement of gigacycle fatigue properties by modified ausforming in 1600 and 2000 MPA-class low-alloy steels. Metall Mater Trans A - Phys Metall Mater Sci 2002;33(11):3421-31.

[7] Bathias C, Drouillac L, Le Francois P. How and why the fatigue S-N curve does not approach a horizontal asymptote. Int J Fatigue 2001;23:S143-51.

[8] Murakami Y, Nomoto T, Ueda T. On the mechanism of fatigue failure in the superlong life regime $\left(N>10^{7}\right.$ cycles). Part I: influence of hydrogen trapped by inclusions. Fatigue Fract Eng Mater Struct 2000;23(11):893-902.

[9] Wang QY, Berard JY, Dubarre A, Baudry G, Rathery S, Bathias C. Gigacycle fatigue of ferrous alloys. Fatigue Fract Eng Mater Struct 1999;22(8):667-72.

[10] Zhou C, Oian G, Hong Y. Fractography and crack initiation of very-high-cycle fatigue for a high carbon low alloy steel. Key Eng Mater 2006;324325:1113-6.

[11] Plumtree A, Untermann N. Long fatigue life critical crack lengths. Fatigue Fract Eng Mater Struct 2010;33(5):320-30.

[12] Abe T, Furuya Y, Matsuoka S. Gigacycle fatigue properties of $1800 \mathrm{MPa}$ class spring steels. Fatigue Fract Eng Mater Struct 2004;27(2):159-67.

[13] Dieter GE. Engineering design. New York: McGraw Hill; 1983.

[14] Stanzl-Tchegg SE. Fracture mechanisms and fracture mechanics at ultrasonic frequencies. Fatigue Fract Eng Mater Struct 1999;22(7):567-79.

[15] Papakyriacou M, Mayer H, Pypen C, Plenk H, Stanzl-Tschegg S. Influence of loading frequency on high cycle fatigue properties of b.c.c. and h.c.p. metals. Mater Sci Eng A 2001.

[16] Marines I, Dominguez G, Baudry G, Vittori JF, Rathery S, Doucet JP, et al. Ultrasonic fatigue tests on bearing steel AISI-SAE 52100 at frequency of 20 and $30 \mathrm{kHz}$. Int J Fatigue 2003;25(9-11):1037-46.

[17] Ebara R. The present situation and future problems in ultrasonic fatigue testing - mainly reviewed on environmental effects and materials' screening. Int J Fatigue 2006;28(11):1465-70.

[18] Wagner D, Ranc N, Bathias C, Paris PC. Fatigue crack initiation detection by an infrared thermography method. Fatigue Fract Eng Mater Struct 2010;33(1):12-21.

[19] Laird C, Charsley P. Strain rate sensitivity effects in cyclic deformation and fatigue fracture. In: Wells JM, Buck O, Roth LD, Tien JK, editors. Proceeding of first international conference on fatigue and corrosion fatigue up to ultrasonic frequencies. Philadelphia: The Metall Soc of AIME; 1982. p. 187-205.

[20] Mayer H. Fatigue crack growth and threshold measurements at very high frequencies. Int Mater Rev 1999;44(1):1-34.

[21] Shiozawa K, Morii Y, Nishino S, Lu L. Subsurface crack initiation and propagation mechanism in high-strength steel in a very high cycle fatigue regime. Int J Fatigue 2006;28(11):1521-32.

[22] Nishijima S, Kanazawa K. Stepwise S-N curve and fish-eye failure in gigacycle fatigue. Fatigue Fract Eng Mater Struct 1999;22(7):601-7.

[23] Qian G, Hong Y, Zhou C. Investigation of high cycle and very-high-cycle fatigue behaviors for a structural steel with smooth and notched specimens. Eng Fail Anal 2010;17(7-8):1517-25.

[24] Sakai T, Lian B, Takeda M, Shiozawa K, Oguma N, Ochi Y, et al. Statistical duplex S-N characteristics of high carbon chromium bearing steel in rotating bending in very high cycle regime. Int J Fatigue 2010;32(3):497-504.

[25] Shiozawa K, Lu L, Ishihara S. S-N curve characteristics and subsurface crack initiation behavior in ultra-long life fatigue of a high carbon-chromium bearing steel. Fatigue Fract Eng Mater Struct 2001;24(12):781-90. 
[26] Ochi Y, Matsumura T, Masaki K, Yoshida S. High-cycle rotating bending fatigue property in very long-life regime of high-strength steels. Fatigue Fract Eng Mater Struct 2002;25(8-9):823-30.

[27] Sakai T, Oguma N, Harada H. Strength level dependence of very high cycle fatigue property in interior inclusion-induced fracture for bearing steel in rotating bending. In: Allison JE, Jones JW, Larsen JM, Ritchie RO, editors. Proceeding of fourth international conference on Very-High-Cycle Fatigue (VHCF-4), USA: TMS; 2007. p. 129-36.

[28] Nakajima M, Tokaji K, Itoga H, Shimizu T. Effect of loading condition on very high cycle fatigue behavior in a high strength steel. Int J Fatigue 2010;32(2):475-80.

[29] Murakami Y, Kodama S, Konuma S. Quantitative evaluation of effects of nonmetallic inclusions on fatigue strength of high strength steel. Trans Jpn Soc Mech Eng 1988;54(500):688-95.

[30] Chinese Aviation Institute. Stress intensity factors handbook. Berlin: Springer; 1993.

[31] Sakai T. Review and prospects for current studies on very high cycle fatigue of metallic materials for machine structural use. In: Allison JE, Jones JW, Larsen JM, Ritchie RO, editors. Proceeding of fourth international conference on VeryHigh-Cycle Fatigue (VHCF-4). USA: TMS; 2007. p. 003-12.

[32] Zhao A, Xie J, Sun C, Lei Z, Hong Y. Prediction of threshold value for FGA formation. Mater Sci Eng A 2011;528(22-23):5872-7.
[33] Hong Y, Zhao A, Qian G. Essential characteristic and influential factors for veryhigh-cycle fatigue behavior of metallic materials. Acta Metall Sin 2009;45(7):769-80.

[34] Mughrabi H. Specific features and mechanisms of fatigue in the ultrahighcycle regime. Int J Fatigue 2006;28(11):1501-8.

[35] Papakyriacou M, Mayer H, Plenk H, Stanzl-Tschegg S. Cyclic plastic deformation of tantalum and niobium at very high numbers of cycles. Mater Sci Eng A 2002;325(1-2):520-4.

[36] Zettl B, Mayer H, Ede C, Stanzl-Tschegg S. Very high cycle fatigue of normalized carbon steels. Int J Fatigue 2006;28(11):1583-9.

[37] Stanzl-Tschegg S, Mughrabi H, Schoenbauer B. Life time and cyclic slip of copper in the VHCF regime. Int J Fatigue 2007;29(9-11):2050-9.

[38] Qian G, Zhou C, Hong Y. Experimental and theoretical investigation of environmental media on very-high-cycle fatigue behavior for a structural steel. Acta Mater 2011;59(4):1321-7.

[39] Hong Y, Zhao A, Qian G, Zhou C. Fatigue strength and crack initiation mechanism of very-high-cycle fatigue for low alloy steels. Metall Mater Trans A - Phys Metall Mater Sci 2011. doi:10.1007/s11661-011-0816-7.

[40] Stein DF, Low JR. Mobility of edge dislocations in silicon-iron crystals. J Appl Phys 1960;31(2):362-9. 